\title{
Strategies of Family, School and Community Linkage to Promote Writing Teaching in Grade One
}

\author{
Ai Jiang \\ School of Humanities and Social Sciences, China Jiliang University, Hangzhou, 310000, China; \\ 494734670@qq.com
}

Keywords: Grade one; Teaching strategy; Home and school community

\begin{abstract}
The low-level writing teaching is the beginning stage of high-level composition. Putting what I think into paper is a big step in the primary school to the language learning. In this process, many students have some difficulties. This article starts with the characteristics of the children's physiology, psychology, living environment, writing preferences, and expression methods. It analyzes the strategy of comprehensively using schools, families, and communities to jointly promote writing teaching in grade one.

The Chinese Language Curriculum Standards call writing in the first phase of Chinese learning as writing, requiring first-year students to be interested in writing, writing what they want to say, writing about what they imagine, and writing about their understanding of the surrounding things. And feelings; in the writing of words, happy to use the words learned in reading and life; according to the needs of expression, learning to use commas, full stops, question marks, exclamation marks. The purpose is that to emphasize writing down the children's minds without having to care too much about the differences of written and Verbal.

First-year children have a limited life circle, spend most of their time on campus, spend part of their time at home, and spend relatively little time in the community. Writing is a kind of subjective learning behavior. Writing is based on life. Accumulation of all kinds of materials in life is particularly important for the writing training of low-level children. Children of this period are particularly rich in imagination, but they are easy to go somewhere. How to guide children to make reasonable imaginations and use this advantage to write? The following are my simple views on the comprehensive use of teaching in schools, families and communities to promote the first-year writing teaching.
\end{abstract}

\section{First, Make Full Use of School Resources}

A school is an organization that educators have systematic and organized educational activities for educators. It is a major place for students to absorb knowledge. School teaching resources refer to all available conditions for the effective implementation of teaching in schools, including teaching aids, cases, and infrastructure. The school resources mentioned in this article mainly refer to classroom resources, including teaching materials and extracurricular reading materials.

\section{(1) Rely on text, imitation sentence}

The first-grade Chinese textbooks are rich in content, full of childlike innocence, and close to students' daily lives. Language usage is standardized. Therefore, relying on the text is an indispensable way to promote first-year writing teaching. American educator Monroe believes that education originated from children's unconscious imitation of adults. Imitation is a relatively simple method of low-level writing.

First of all, let students learn to imitate to write a sentence. Writing in the first grade must start with the simplest sentence and instill the concept of a complete sentence rather than writing a few phrases. This is the minimum requirement. When the students have the concept of a complete sentence in mind, the teacher can select some of the good sentences in the text, extract the necessary elements of the sentence, and allow students to copy and write it. For example, the sentence "Sunshine makes the trees taller and the sunlight makes the seedlings greener," extracts the sentence "Sunshine makes () more ()" for students to practice. Some students with weak foundations can say simple sentences such as 
"Sunshine makes flowers more red, sunshine makes grass taller." Students with a good language foundation will use good words drawn from other texts to use sentence patterns. For example, my student Junyou Wu wrote such a sentence: Sunlight makes gardens more colorful, and sunshine makes children more Vibrant. After learning this sentence, when I replaced the subject with "big snow", "mother", etc., the children could say a complete or even beautiful words.

Relying on the text, the imitation sentence pattern not only allowed the children to have a concept of writing a complete sentence, but also taught them the initial writing skills and deepened the understanding of the text of the teaching material.

\section{(2) Using of illustrations, seeing pictures and writing}

A feature of the writing of the first-grade language textbook is that the book contains a large number of illustrations, each of which has at least one illustration related to the text. The text illustrations are not only full of childlike interest, they are colorful and in line with the psychological characteristics of children in the first grade. They are also exquisite in style, and the expressions and movements of the characters in the painting are at a glance. Many first-grade teachers are bothered by the material of seeking pictures and words when they are training their children to write words. Now, it is not necessary to look at the pictures. Textual pictures are the simplest and most practical writing materials.

The compilation of the Chinese textbook for the first year of the book "Putless little hands" on page 41 is marked with large illustrations. After learning the text, I led the children to carefully observe the illustrations and talk about what happened to the Lan Lan family this day. Soon the children raised their hands: "On this day, Lan Lan painted a pair of chubby little hands. Dad liked it. Hanging Lan Lan's paintings on the wall, Lan Lan was happy." The children can already make things clear. Then, I guide them again to observe the movement of Lan Lan and Dad. Soon afterwards, the children raised their hands: "On this day, Dad put Lan Lan's "Cute Little Hands" on the wall, and Lan Lan was dancing with joy." The child's appearance was beyond my expectation. I praised the child with the idiom "Dance to dance." Next, I led the children to use their imagination to guess what Dad or Lan Lan would say. The atmosphere began to warm up. The children talked rapturously. Someone moved the conversation between Lan Lan and Dad in the text to the writing. Someone else opened up another way and wrote and directed another scene.

Since then, the child's enthusiasm for writing has greatly increased. A first-grade child can't write an essay with a title like a senior's older brother and sister. When your child can't write a flexible sentence, try to give him a vivid picture to help stimulate the child. Reasonable imagination. Clever use of illustrations to make writing more effective.

\section{(3) Respecting children's songs and developing a sense of language}

The children's songs are full of peculiar imagination, the content is close to daily life, and the form is very rhythmic. It is the earliest literary form that the Chinese language can understand for the first-year children. The children in my class particularly like to read early and give them a text. Children can read it many times over and over again. The sound lasts forever. In the first-grade textbooks for the first-grade Chinese textbooks, the most popular texts for them are "Yue Yun Ge", "Yuan Ye Yuan Yuan" and "Shear Window Cut".

\section{Dig Deeper Into the Details of Life and Revitalize the Source of Written Writing}

Art comes from life and life. Students in the first grade of primary school see life as naive and they cannot rationally view things in life. So how do you make younger writers have something to say? We need to bring our children into the natural world and encourage them to extend their senses throughout their lives and accumulate writing materials.

\section{(1)Record the language of life in time}

Life is like a box of chocolates. You never know what the next one is. The joys, sorrows and joys of life are worth being recorded. Teachers with low grades all know that although children of lower grades sometimes have incomplete words, their feelings are very keen, and sometimes even the phrasing is constantly in progress. 
There was a young boy named Huang Zhetang. During the intersessional period, I saw him kneeling under the shadow of a mottled tree and he didn't know what to watch. The time lasted for about 5 minutes. I couldn't help but walked over. Squat down and watch him. See the companion, he naively said: "Every yellow and yellow shadow is the autumn leaves." I was shocked, the sun through the leaves on the playground yellow line is not like the leaves it? Is September not Fall? The shadow moves with the wind, this little guy is vivid, isn't it?

This was the first time in my teaching career that I was shocked by the child's delicate emotional experience. If you can record the golden sentence in your life and accumulate the individual language, it is impossible to write monotony. At the same time, if the children's own sentences are affirmed, the enthusiasm for writing will be unimaginable.

\section{(2)Conservation of animals and plants and accumulation of life experience}

First-year children are full of passion and curiosity about life. They like all kinds of interesting things. In order to cultivate children's sense of responsibility and careful psychological qualities, many parents choose to have their children preserve some animals and plants. This has accumulated important material for children's writing.

In the context of free writing, many of the works handed in by the students are such writings as "My Little White," "My Garden," and "Grandma's White Rabbit." Because they had personally maintained them, because they had some practical things with them, so when doing such writing, the children were more able to write and have something to say.

\section{Flexible Use of Community Resources, So That Children Can Write}

Community teaching resources refer to all resources available in the community to help teaching. The community resources in this article mainly refer to the community environment in which students live and the social practices they contain

In the winter holiday of 2017 , the students participated in various social activities. For example, washing feet and making dinner for the centenarians left a deep impression on the children's hearts. This is also an excellent material for writing.

In addition to using the above teaching resources to advance the first-year writing teaching, it is also necessary to play a good role in the joint action of homes, schools, and communities.

The persistence and identity of educational activities determine that families, schools, and communities must form a joint force to ensure effective school teaching. On the contrary, there will be mutual demolition. In the actual educational life, we often hear some teachers say: "Our intensive education has just made little progress in the children's writing. After returning home, the parents' words have been weakened or even cancelled out. We have worked hard for several days or even months." Therefore, in addition to synthesizing tripartite teaching resources, written writing education also needs to promote concerted efforts among families, schools, and communities in order to do more with less.

\section{References}

[1]Using Picture Book Resources to Promote Students' Personal Writing [J]. Fan Xia. National Excellent Composition (writing and reading teaching research). 2016-02

[2] Adopt multiple ways to enrich the low-level writing content [J]. Chai Qiangming. Reference for primary school teaching. 2016-07

[3] Problems and Teaching Strategies in Reading and Writing of Junior High School Primary School Students [J]. Wu Shujuan. Educational Observation (second half). 2015-16

[4] Problems and Countermeasures in Early Years Writing and Writing Teaching[J]. Ye Fuquan. Primary School Chinese. 2015-04

[5] "Graffiti Diary" : Our Journey of Happy Writing [J]. Lu Huikai. New Composition (Primary School Composition and Innovative Teaching). 2015 Z1 
[6]Drawing Diaries for Students to Write Words and Navigating - - The Exploration of Low-level Writing Teaching[J]. Dai Juanli. Xue Zhou. Journal No. 31, 2014

[7] The problem and countermeasures of reading and writing in primary school Chinese language teaching [J]. Wu Yanling. Chinese language construction. 2014 